\title{
Identification and Antimicrobial Properties of Malaysian Mangrove Actinomycetes
}

\author{
Suhaidi Ariffin", Mohd Faiz Foong Abdullah*, Sharifah Aminah Syed Mohamad* \\ ${ }^{\#}$ Faculty of Applied Sciences, Universiti Teknologi MARA, 35400 Tapah, Perak, Malaysia \\ E-mail: suhaidi@perak.uitm.edu.my \\ ${ }^{*}$ Faculty of Applied Sciences, Universiti Teknologi MARA, 40450 Shah Alam, Selangor, Malaysia \\ E-mail:mohdf184@salam.uitm.edu.my,sharifah459@salam.uitm.edu.my
}

\begin{abstract}
The mangrove area is one of the more unique and less studied habitats for the discovery of biologically active secondary metabolites from potential actinomycetes. For this reason, isolation, characterization and screening of antimicrobial properties of actinomycetes from mangrove soils collected at the selected mangrove areas in Malaysia were conducted. A total of 73 actinomycetes were isolated. Of these, $9.6 \%$ (direct broth culture) and $8.2 \%$ (ethyl acetate extract) of these isolates demonstrated antimicrobial activities active against Staphylococcus aureus, Bacillus subtilis, Candida albicans as well as Saccharomyces cerevisiae by disc diffusion assay. Hexane extracts, however, exhibited no activity. A modified microdilution plate assay showed that $16.4 \%$ (ethyl acetate extract) of these strains were able to generate antimicrobial compounds active against Staphylococcus aureus, Bacillus subtilis, and Candida albicans. In addition, morphological observations and 16S rRNA sequence analysis indicate the presence of representative species from at least 3 genera Streptomyces, Pseudonocardia and Saccharomonospora. Thus, Malaysian mangrove soils could be an interesting source to explore for antimicrobial secondary metabolites and considered to have a diversity of marine actinomycetes.
\end{abstract}

Keywords - mangrove; actinomycetes diversity; antimicrobial properties; secondary metabolites

\section{INTRODUCTION}

The mangrove forest is a largely unexplored and unique habitat due to its agro-ecological condition. They are occasionally covered with low, moderate or high saline water [1] in which the different degree of salinity eventually become an extreme habitat to all living things [2]. In addition, the marine realm is considered as highly productive ecosystem [3], [4] in bearing new species of microorganisms, although little is known about the microbial communities living therein [5]. This ecosystem is situated at the interphase between the terrestrial and marine environment and supports a rich and diverse group of microorganisms [1]. There is evidence that mangrove soils contain high populations of diverse actinomycetes [5], [6] and some of them were identified as novel actinomycetes [7], [8].

Actinomycetes are filamentous and sporulating Grampositive bacteria characterized by a complex life cycle belonging to the phylum Actinobacteria. Actinobacteria are widely distributed in both terrestrial and aquatic ecosystems. They play a pivotal role as a decomposer of complex mixtures of polymers in dead plants, animals as well as fungal materials [9]. In addition, they are also known as degrader as they recycle the nutrients associated with intractable polymers such as chitin, keratin and lignocelluloses in soil biodegradation and humus formation [10]-[12]. The decomposition and degradation activities resulted in the production of volatile substance like geosmin, which is responsible for the characteristic 'wet earth odour' [13] and exhibited diverse physiological and metabolic properties, such as extracellular enzymes [11], [14]. They are all believed to have high guanine and cytosine content in their DNA and identified as the most economically and biotechnologically valuable bacteria that provide many important bioactive compounds [15].

Antimicrobials are extremely valuable tools for the prevention and treatment of infectious diseases and screenings of new metabolites for novel antibiotics from actinomycetes are becoming a routine. For example, a study by [16] reported the potential antimicrobial of actinomycetes from sediments in Trondheim Fjord. Approximately twothirds of naturally occurring antibiotics have been isolated from actinomycetes [17] and most of the bioactive microbial metabolites have been isolated from streptomycetes [18]. However, most of the metabolites were derived from terrestrial origin. Those from marine are still relatively unknown, and moreover, the interest in the marine microflora has increased from the last 20-30 years ago. 
Recently, there has been an explosion of information on novel bioactive compounds isolated from marine microbes in an effort to further explore the relatively untapped marine microbes and their secondary metabolites for drug discovery [19]. In order to get better odds in finding new or novel microorganisms and compounds, exploring new habitats has been one of the most successful strategies. This can be achieved by isolating the microorganisms from the unique environment. Diverse regions like mangrove, deep subsurface, deep sea and sites that have an extreme temperature, salinity or $\mathrm{pH}$ frequently produce novel microorganisms and therefore provide the potential for novel compounds [20].

\section{MATERIAL AND METHOD}

\section{A. Collection of Samples}

Soil samples were randomly collected from 11 different mangrove locations (Fig. 1) including Tanjung Harapan, Pantai Morib, Pantai Kelanang and Pantai Remis (Selangor), Pantai Cherating (Pahang), Kuala Muda (Kedah), Umbai (Melaka), Palm Beach (Sabah) Pasir Panjang (Negeri Sembilan), Pantai Chendering (Terengganu) and Pantai Tok Bali (Kelantan). At each location, 3 to 5 soil spot samples were collected at a depth of 2 to $10 \mathrm{~cm}$ from the surface. Soil samples were stored in sterile plastic bags and were either examined on the day of sampling or on the following day. Samples were stored at $4{ }^{\circ} \mathrm{C}$ prior to investigation.

\section{B. Isolation and Cultivation of Actinomycetes}

Five different isolation medium were prepared. All media were incorporated with $50 \mathrm{mg} / \mathrm{L}$ of cycloheximide to reduce numbers of unwanted moulds, yeasts, as well as fungi. The medium was also supplemented with $3 \%$ final concentration of sodium chloride $(\mathrm{NaCl})$ as an alternative to replace sea water. All ingredients were completely dissolved in $500 \mathrm{~mL}$ of distilled water and adjusted to $\mathrm{pH} 7.0$ to $7.2( \pm 0.2)$, depending on the type of media, prior to sterilization. All media were sterilized by autoclaving at $121^{\circ} \mathrm{C}$ for 15 minutes.

Dilutions of soil were plated out onto 5 different selective isolation media, humic acid vitamin agar $(0.5 \mathrm{~g}$ humid acid, $0.25 \mathrm{~g} \mathrm{Na}_{2} \mathrm{HPO}_{4}, 0.855 \mathrm{~g} \mathrm{KCl}, 0.025 \mathrm{~g} \mathrm{MgSO}_{4} .7 \mathrm{H}_{2} \mathrm{O}, 0.005$ g $\mathrm{FeSO}_{4} .7 \mathrm{H}_{2} \mathrm{O}, 0.01 \mathrm{CaCO}_{3}, 25 \mathrm{~mL}$ Vitamin $\mathrm{B}_{6}$ and $9.0 \mathrm{~g}$ bacteriological agar. Final concentration of $5 \mathrm{mg} / \mathrm{L}$ of filter-sterilized Vitamin $\mathrm{B}_{6}$ was added after the agar was autoclaved and cooled to $60^{\circ} \mathrm{C}$ ); starch casein nitrate agar (5.0 g soluble starch, $0.15 \mathrm{~g}$ casein $1.0 \mathrm{~g} \mathrm{KNO}_{3}, 1.0 \mathrm{~g}$ $\mathrm{NaCl}, 0.025 \mathrm{~g} \mathrm{MgSO}_{4} .7 \mathrm{H}_{2} \mathrm{O}, 0.01 \mathrm{CaCO}_{3}, \mathrm{FeSO}_{4} .7 \mathrm{H}_{2} \mathrm{O}$ and $9.0 \mathrm{~g}$ bacteriological agar); starch yeast extract agar (1.0 g yeast extract, $5.0 \mathrm{~g}$ soluble starch and $9.0 \mathrm{~g}$ bacteriological agar); glucose asparagines agar $\left(0.25 \mathrm{~g} \mathrm{~K}_{2} \mathrm{HPO}_{4}, 0.25 \mathrm{~g} \mathrm{~L}\right.$ asparagine, $5.0 \mathrm{~g}$ glucose and $7.5 \mathrm{~g}$ bacteriological agar) and yeast malt extract dextrose agar $(2.0 \mathrm{~g}$ yeast extract, $5.0 \mathrm{~g}$ malt extract, $2.0 \mathrm{~g}$ dextrose and $10.0 \mathrm{~g}$ bacteriological agar).

\section{Morphological Characterization}

Each isolate was examined both macroscopically and microscopically. All isolates were sub-cultured onto YMDA for standardization purposes and incubated at $30^{\circ} \mathrm{C}$ for 7 to 10 days. Morphological characters of isolates were visually observed from the plate, whereas microscopic characterization was done by cover slip-buried method [21], [22].

Isolates were examined on the basis of their colony morphology. The aerial and substrate mycelium colour were recorded from matured isolates. The melanin pigments were determined by the ability of the isolates to change the original colour of media. However, the diffusible pigments were examined in broth medium and recorded during the fermentation process.

Isolates were streaked at the edge between the cover slip (impregnated at an angle of $45^{\circ}$ ) and solid agar. Microscopic details such as hyphal reproduction structures and spores were examined and recorded after 7 days incubation using a light microscope with magnifications up to $100 \mathrm{X}$.

\section{Extraction of DNA from Pure Cultures}

Selected bacteria colonies from the plate were picked and inoculated in $100 \mathrm{~mL}$ of sterile TYB and SCNB, depending on the medium they grew at $30^{\circ} \mathrm{C}$ for 7 days.

A volume of $100 \mu \mathrm{L}$ of DNAzol (DNAzol® Direct, Molecular Research Center, Inc., USA) solution was used for DNA extraction. The sample was vortex vigorously before heated for 2 to 7 hours in a dry bath for complete cell lysis.

Alternatively, the DNA was extracted by using DNeasy® Blood and Tissue Kit (Qiagen, Germany) following manufacturer's instruction.

\section{E. PCR Amplification}

The PCR reactions were performed in a final volume of $25 \mu \mathrm{L}$ which composed of 1 X Green GoTaq ${ }^{\circledR}$ Flexi Buffer, 1.0-4.0 Mm $\mathrm{MgCl}_{2}, 0.2 \mathrm{Mm}$ PCR Nucleotide Mix, 0.1-1.0 $\mu \mathrm{M}$ of upstream (PA) and downstream primers (PB) each, $1.25 \mathrm{u}$ GoTaq ${ }^{\circledR}$ DNA Polymerase, $<0.5 \mu \mathrm{g} / 50 \mu \mathrm{L}$ template DNA and Nuclease-free water. The PCR products were separated by $1.0 \%$ agarose gel electrophoresis and purified using QIAquick® PCR purification kit (Qiagen, Germany). The PCR reaction was done under following conditions: initial denaturation at $94^{\circ} \mathrm{C}$ for 4 minutes; 30 cycles of $94^{\circ} \mathrm{C}$ for 1 minute, $55^{\circ} \mathrm{C}$ for 1 minute, and $72^{\circ} \mathrm{C}$ for 2 minutes; and a final extension at $72^{\circ} \mathrm{C}$ for 10 minutes. The amplification of DNA was done using a pair of primer, PA (5'AGAGTTTGATCCTGGCTCAG-3')-PB (5'-AAGGAGGT GATCCAGCCGCA-3') which specifically target the 16S rRNA gene [23] and a universal primer. (All the PCR reagents were from Promega, Spain or otherwise stated).

\section{F. Sequencing Analysis}

The purified PCR samples were sent to the third party service provider (AITbiotech Company, Singapore) for DNA sequencing and assembled using DNA Baser (Heracle BioSoft SRL, Romania) (www.DnaBaser.com). The assembled sequence was submitted to the BLAST function of GenBank (www.ncbi.nlm.nih.gov/BLAST/). 


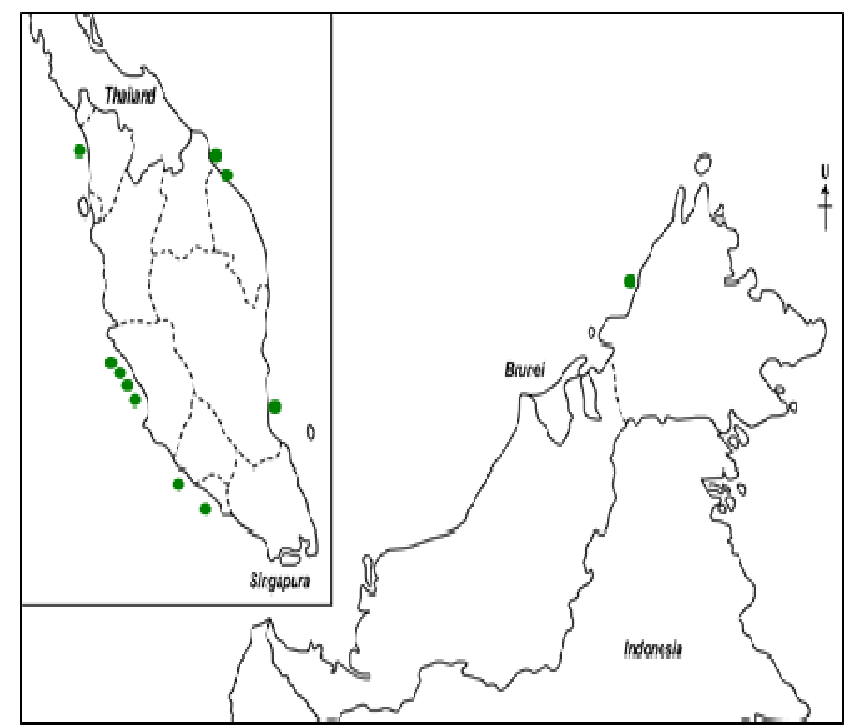

Fig. 1 Distribution of sampling locations. Note: TH (Tanjung Harapan); PM (Pantai Morib); PK (Pantai Kelanang); PR (Pantai Remis); PC (Pantai Cherating); KM (Kuala Muda); U (Umbai); PB (Palm Beach); PD (Pasir Panjang); PG (Pantai Chendering); TB (Pantai Tok Bali).

\section{G. Preparation of Crude Extract}

The broth medium used to harvest metabolites was tryptone yeast extract broth, TYB (2.5 g tryptone and $1.5 \mathrm{~g}$ yeast extract) and starch casein nitrate broth, SCNB (5.0 g soluble starch, $0.15 \mathrm{~g}$ casein $1.0 \mathrm{~g} \mathrm{KNO}_{3}, 1.0 \mathrm{~g} \mathrm{NaCl}, 0.025$ $\mathrm{g} \mathrm{MgSO}_{4} .7 \mathrm{H}_{2} \mathrm{O}, 0.01 \mathrm{CaCO}_{3}$ and $0.005 \mathrm{~g} \mathrm{FeSO}_{4} .7 \mathrm{H}_{2} \mathrm{O}$ ).

\section{H. Crude Extract Prepared by Using Rotary Evaporator}

Each isolate was inoculated in $100 \mathrm{~mL}$ of TYB and SCNB medium and incubated at $30^{\circ} \mathrm{C}$ for 10 to 14 days in an incubator shaker at $170 \mathrm{rpm}$. The matured cultured broth was centrifuged, filtered and extracted with an equal volume of solvents (hexane and ethyl acetate). The extract was vigorously shaken at $200 \mathrm{rpm}$ at room temperature for 1 to 2 hours before the organic solvents phase was taken out and concentrated by using a rotary evaporator. The concentrated extract was transferred to a pre-weighed vial, dried by air drying and the dry weight was determined (1.0 to $4.0 \mathrm{mg}$ ). All dried extracts were dissolved in the same solvents prior to bioassay screening.

\section{Crude Extract Prepared by Air Drying}

The preparation was similar as previously described. However, the total volume used to culture and extract the sample was reduced to $30 \mathrm{ml}$ and the crude was recovered by air drying. The organic solvent phase was transferred to a pre-weighed vial, dried by air drying and the dry weight was determined ( 0.1 to $3.6 \mathrm{mg}$ ). All dried extracts were dissolved using $10 \%$ methanol prior to bioassay screening.

\section{J. Screening for Antimicrobial Activity}

The antimicrobial activity of the isolates from both direct culture broth and crude extracts were determined. The conventional disc diffusion method and a resazurin-based microtiter plate method were applied. The test organisms used were S.aureus, B.subtilis, E.coli, P.aeruginosa, C.albicans and S.cerevisiae. The OD readings of overnight culture of the test organisms were measured $\left(\mathrm{OD}_{600}\right.$ for bacteria and $\mathrm{OD}_{630}$ for fungi and yeast) and diluted within the range of 0.03 to 0.05 before they were used for screening.

For direct culture broth, the isolate was inoculated in 5 $\mathrm{mL}$ of TYB and SCNB medium and incubated at $30^{\circ} \mathrm{C}$ for 7 days in an incubator shaker at $170 \mathrm{rpm}$.

For crude extracts, the extracts obtained were dissolved in $2 \mathrm{~mL}$ solvent (hexane and ethyl acetate) giving the concentration of each sample from 500 to $2000 \mu \mathrm{g} / \mathrm{mL}$. Sterilized $6 \mathrm{~mm}$ whatman paper disc was dipped into the samples and dried before transferred onto seeded agar medium. The content of samples on the disc was calculated ( 1 to $4 \mu \mathrm{g})$. Streptomycin $(0.8 \mu \mathrm{g})$, nystatin $(0.4 \mu \mathrm{g})$ and chloramphenicol $(0.8 \mu \mathrm{g})$ antibiotics were used as positive control for bacteria, fungi, and yeast respectively. The uninoculated sterile broth was used as the negative control. All plates were incubated at $30^{\circ} \mathrm{C}$ for 24 hours for bacteria and 48 hours for fungi and yeast.

For the modified microtiter plate method [24], each extract was dissolved in $2 \mathrm{~mL}$ of $10 \%$ methanol and shaken using vortex mixer for complete dissolve. $10 \mu \mathrm{L}$ of overnight test organism were transferred individually into 96-well plates followed by $30 \mu \mathrm{L}$ of extract. Each well was filled up with $60 \mu \mathrm{L}$ of sterilized distilled water to make up100 $\mu \mathrm{L}$ final volume. The plate was incubated at $30^{\circ} \mathrm{C}$ overnight. The cell viability was determined by the addition of $20 \mu \mathrm{L}$ of $0.5 \mathrm{mM}$ blue dye resazurin solution. Resazurin is a growth indicator and bacteria viability was indicated by a colour change to pink. The positive control for this activity was the streptomycin $(0.04 \mu \mathrm{g} / \mu \mathrm{L})$ and nystatin $(0.02 \mu \mathrm{g} / \mu \mathrm{L})$ for bacteria and fungi respectively. The negative control used was the $10 \%$ DMSO. The control well was filled up with 80 $\mu \mathrm{L}$ of sterilized distilled water.

\section{RESULTS AND DISCUSSION}

\section{A. Marine Actinomycetes Isolated from Mangrove Soils}

A total of 73 actinomycetes were isolated from mangrove soil samples collected at eleven different mangrove locations in Malaysia. Among these isolates, 38 strains were recovered on SCNA followed by 14, 9, 8 and 4 strains were obtained on HVA, YMD, GAA and SYA respectively (Table 1). The SCNA with the addition of $3 \%$ final concentration of $\mathrm{NaCl}$ was the best growth media in this study (Table 1). The highest percentage of actinomycete isolates (18\%) was obtained from the Pantai Kelanang mangrove locations and the lowest (1\%) from Umbai and Pantai Cherating mangrove location as shown in the Fig. 2.

Among 73 isolates, it was found that the predominant colors produced by these actinomycetes were white $(34 / 48 \%)$ and grey $(18 / 25 \%)$, whereas others formed brown $(7 / 10 \%)$, creamy $(5 / 7 \%)$, orange $(2 / 3 \%)$, pink $(1 / 1 \%)$, green $(1 / 1 \%)$, peach $(1 / 1 \%)$, red $(1 / 1 \%)$ and yellowish $(1 / 1 \%)$. Nineteen isolates produced melanin pigment, however, only 6 isolates produced diffusible pigment into the broth. Most of the isolates produced spores of hyphal origin and developed in chains, but one isolate (PMS2B) was found to produce singly spore on the tip of the side branches hyphal wall as shown in Fig. 3. 
TABLE I

Number of ACTINOMYCETES FROM DifFERENT SELECTIVE ISOLATION MEDIUM

\begin{tabular}{|l|c|c|c|c|c|c|}
\hline $\begin{array}{l}\text { Mangrove } \\
\text { Location }\end{array}$ & \multicolumn{7}{|c|}{ Number of Isolates } \\
\cline { 2 - 7 } & HVA & SCNA & YMD & GAA & SYA & Total \\
\hline $\begin{array}{l}\text { Tanjung } \\
\text { Harapan }\end{array}$ & 2 & 2 & 0 & 0 & 0 & 4 \\
\hline $\begin{array}{l}\text { Pantai } \\
\text { Morib }\end{array}$ & 1 & 3 & 0 & 5 & 3 & 12 \\
\hline $\begin{array}{l}\text { Pantai } \\
\text { Kelanang }\end{array}$ & 4 & 4 & 3 & 2 & 0 & 13 \\
\hline $\begin{array}{l}\text { Pantai } \\
\text { Remis }\end{array}$ & 1 & 3 & 4 & 0 & 0 & 8 \\
\hline $\begin{array}{l}\text { Pantai } \\
\text { Cherating }\end{array}$ & 0 & 1 & 0 & 0 & 0 & 1 \\
\hline $\begin{array}{l}\text { Kuala } \\
\text { Muda }\end{array}$ & 2 & 4 & 0 & 1 & 1 & 8 \\
\hline Umbai & 0 & 1 & 0 & 0 & 0 & 1 \\
\hline $\begin{array}{l}\text { Palm } \\
\text { Beach }\end{array}$ & 2 & 2 & 2 & 0 & 0 & 6 \\
\hline $\begin{array}{l}\text { Pasir } \\
\text { Panjang }\end{array}$ & 1 & 1 & 0 & 0 & 0 & 2 \\
\hline $\begin{array}{l}\text { Pantai } \\
\text { Chendering }\end{array}$ & 1 & 10 & 0 & 0 & 0 & 11 \\
\hline $\begin{array}{l}\text { Pantai Tok } \\
\text { Bali }\end{array}$ & 0 & 7 & 0 & 0 & 0 & 7 \\
\hline Total & 14 & 38 & 9 & 8 & 4 & 73 \\
\hline
\end{tabular}

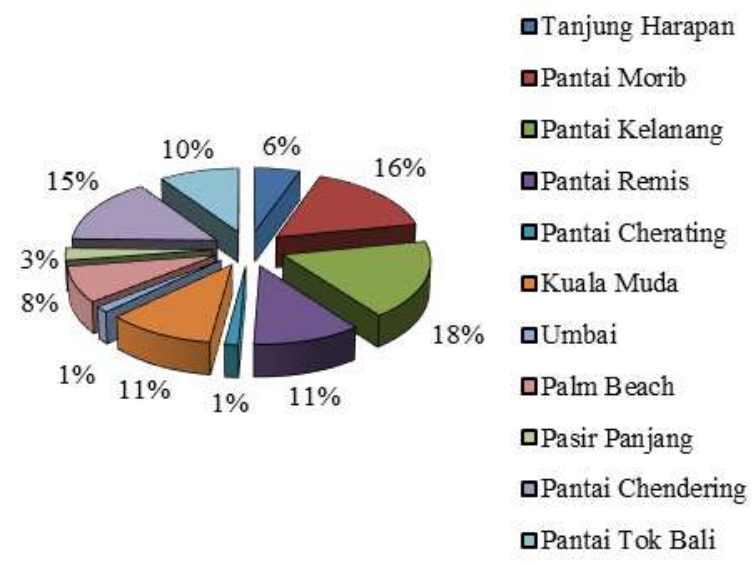

Fig. 2 Percentage of actinomycete isolates per sampling locations

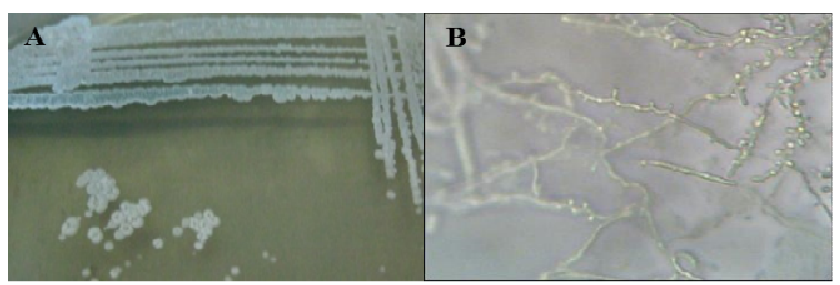

Fig. 3 The (A) macroscopic and (B) microscopic characteristics of Saccharomonospora sp. (PMS2B)

Malaysia is a country that has a vast area of mangrove forests [25]. A total of 11 mangrove environments were chosen for sampling from different regions of Malaysia including east coast, west coast and east Malaysia. Mangroves are unique especially in terms of their adaptation in response to harsh environments. It is believed that metabolites produced by marine actinobacteria isolated from this environment may be different from those terrestrial.
Indeed, the mangrove environment may become a priceless natural source that can be discovered for novel actinomycetes which potentially produce new chemical structures [42] of bioactive compounds. The isolation of marine actinomycetes from mangrove soils has been reported by [5], [8], [26]. In fact, novel actinomycete, Streptomyces xiamenensis was successfully isolated from the mangrove sediment in Fujian Province, China [27] and Actinomadura maheshkaliensis isolated from mangrove rhizosphere soil in Maheshkhali, Bangladesh [8]. The success in isolation of actinomycetes from Malaysian mangrove soil in this study has evidently supported studies by [5], [8], [26]. Remya and Vijayakumar [28] revealed that SCNA was the best medium for maximal growth of marine actinomycetes. However, Hayakawa and Nonomura [29] reported that HVA was the best media to support the development of actinomycetes as compared to colloidal chitin agar (CCA), GAA and SCNA. Therefore, the carbon and nitrogen content greatly influenced the growth numbers of actinomycetes. Additionally, the current study verified that mangrove environment in Malaysia contains considerable potential actinomycetes to be explored its uniqueness, especially from soils sample. Thus, novel actinomycetes isolated from unexplored marine habitats were proven to be a valuable source of new bioactive compounds [30], [31].

\section{B. 16S rRNA Gene Sequencing Analysis of Selected Marine Actinomycete Isolates}

Analysis of the partial 16S rRNA gene sequence of KMS1, KMH2, KMY9, THS1, PCS1, PMG1A, PMS2B and THH3 revealed that they belong to the genera Streptomyces, Saccharomonospora, and Pseudonocardia. THS1, PCS1 and PMG1A were successfully identified up to species level (Table 2). PMS2B isolate that possesses distinct spore arrangement from others belonged to genus Saccharomonospora.

TABLE III

THE IDENTITY OF ISOLATES BASED ON 16S RRNA GENE SEQUENCES ANALYSIS

\begin{tabular}{|l|l|c|}
\hline Designation & Closest Cultivated Species & Identity (\%) \\
\hline KMS1 & Streptomyces sp. JF917314.1 & 100 \\
\hline KMH2 & Streptomyces sp. EU741233.1 & 99 \\
\hline KMY9 & Streptomyces sp. JF917314.1 & 100 \\
\hline THH3 & Pseudonocardia sp. JQ690547.1 & 99 \\
\hline THS1 & Streptomyces variabilis & 98 \\
\hline PCS1 & Streptomyces daghestanicus & 100 \\
\hline PMS2B & $\begin{array}{l}\text { Saccharomonospora sp. } \\
\text { JF806667.1 }\end{array}$ & 100 \\
\hline PMG1A & Streptomyces olivaceus & 100 \\
\hline
\end{tabular}

It is indisputable that mangrove environment also provides the diversity of actinomycetes. Sequencing and analysis [43] of the partial 16S rRNA from selected isolates displayed the presence of members affiliated to actinobacterial genera of Streptomyces, Pseudonocardia, and Saccharomonospora. The guanine-cytosine (GC) contents were calculated from the DNA sequence of the 7 marine actinomycete isolates using DNA/RNA GC Content Calculator available online (www.endmemo.com/bio/ gc.php). The GC content ranges between $59.1 \%$ and $59.9 \%$ 
in all the 7 sequences. A study by [32] using 20 Streptomyces strains isolated from rhizosphere soil of Rhizphora mucronata, Manakkudy estuary of Arabian Sea, Tamil Nadu, India displayed the similar result in which the GC contents of the strains range between 58 and $59.6 \%$. Another potential isolate designated as A2 obtained from rhizosphere soil by [33] exhibited strong antimicrobial activity. This Streptomyces sp. A2 was identified as Streptomyces rameus KCTC 9767 and its GC content was also reported as $59 \%$. Although only three different genera of actinomycetes have been discovered, this study proved that Malaysian mangrove contained a considerable diversity of actinobacteria. It is believed that more genera will be revealed if more locations can be sampled or more isolation medium can be used. However, the high actinobacterial diversity found in mangrove environment can be supported as reported by [5] and several others [8], [34]. In [5] had been successfully classified thirteen genera include Actinomadura, Microbispora, Nonomuraea, Actinoplanes, Micromonospora, Verrucosispora, Arthrobacter, Isoptericola, Micrococcus, Mycobacterium, Nocardia, Rhodococcus, and Streptomyces. Even though the diversity of actinobacteria from mangrove environment in Malaysia is not yet unraveled, it can be suggested that they may be a rich source for discovery of new anti-infective agents.

\section{Bioactivity of Marine Actinomycetes}

The antimicrobial activities of the isolates are summarized in Table 3. According to the result obtained, 14 isolates exhibited positive antimicrobial activity against at least one test organism used. For the disc diffusion method, 9.6\% and $8.2 \%$ showed activity by direct culture and ethyl acetate extract respectively. However, $16.4 \%$ of ethyl acetate extract was active as an antimicrobial agent from microtiter plate method using resazurin as an indicator. Among these 14 isolates, KMS1, THS1, and THS2 showed consistent positive antimicrobial activity from all 3 different approaches. The KMS1 isolate was active against S.aureus and B.subtilis, whereas THS1 and THS2 were active against B.subtilis only. Thus, they showed activity only against Gram-positive test organisms. On the other hand, 4 isolates, PCS1, PMH1A, PMS1B and PDS105 exhibited activity against C.albicans. However, only PCS1 isolate was active against S.cerevisiae. None of the isolates were active against Gram-negative test organisms. Fig. 4 shows the example of an antibacterial activity from THS1 isolate against B.subtilis by disc diffusion method.

For ethyl acetate extract, 8 samples from microtiter plate method and 6 isolates from disc diffusion method displayed antibacterial activity against B.subtilis. Moreover, for activity against S.aureus, 4 samples of the same extract exhibited activity by microtiter plate method and 2 samples produced activity by disc diffusion method. For antiC.albicans, 3 samples were found active from microtiter plate method and only 1 sample showed activity by disc diffusion method. Therefore, microtiter plate method was found to be more preferable as compared to disc diffusion method in this study.

The antimicrobial production from marine-derived actinomycetes has been reported by [15], [16], [18]. In addition, bioactive compounds act as antibacterial and antifungal from marine actinomycetes have been elucidated, such as erythromycin [35] isolated from Saccharopolyspora erythrae, oxytetracycline [36] obtained from Streptomyces rimosus, rapamycin [37] as antifungal from Streptomyces hygroscopicus and many more. Among actinomycetes, Streptomyces are known as the most valuable genera in producing active compounds [38] and recently there has been increasing number of novel metabolites possessing potent bioactivity isolated from marine-derived Streptomyces [39], [40].

TABLE IIIII

ANTIMICROBIAL ACTIVITIES OF ACTINOMYCETES By USING THREE DifFERENT APROACHES

\begin{tabular}{|c|c|c|c|c|c|c|c|c|c|c|c|c|c|c|c|c|c|c|}
\hline & \multicolumn{18}{|c|}{ Test Organisms } \\
\hline & \multicolumn{6}{|c|}{ Gram Positive } & \multicolumn{6}{|c|}{ Gram Negative } & \multirow{2}{*}{\multicolumn{3}{|c|}{$\begin{array}{c}\text { Fungi } \\
\text { C.albicans }\end{array}$}} & \multirow{2}{*}{\multicolumn{3}{|c|}{$\begin{array}{c}\text { Yeast } \\
\text { S.cerevisiae }\end{array}$}} \\
\hline & \multicolumn{3}{|c|}{ S.aureus } & \multicolumn{3}{|c|}{ B.subtilis } & \multicolumn{3}{|c|}{ E.coli } & \multicolumn{3}{|c|}{ P.aeruginosa } & & & & & & \\
\hline & D & $\mathbf{S}$ & $\mathbf{M}$ & D & $\mathbf{S}$ & $\mathbf{M}$ & D & $\mathbf{S}$ & $\mathbf{M}$ & D & $\mathbf{S}$ & $\mathbf{M}$ & D & $\mathbf{S}$ & $\mathbf{M}$ & D & $\mathbf{S}$ & $\mathbf{M}$ \\
\hline PCS1 & - & - & - & - & - & - & - & - & - & - & - & - & + & - & + & + & - & - \\
\hline THS1 & - & - & - & + & + & + & - & - & - & - & - & - & - & - & - & - & - & - \\
\hline THS2 & - & - & - & + & + & + & - & - & - & - & - & - & - & - & - & - & - & - \\
\hline KMS1 & + & + & + & + & + & + & - & - & - & - & - & - & - & - & - & - & - & - \\
\hline KMS2 & - & - & - & - & - & + & - & - & - & - & - & - & - & - & - & - & - & - \\
\hline PMG1A & - & - & - & + & + & - & - & - & - & - & - & - & - & - & - & - & - & - \\
\hline PMH1A & - & - & - & - & + & - & - & - & - & - & - & - & - & - & + & - & - & - \\
\hline PMS1B & - & - & - & - & - & - & - & - & - & - & - & - & - & - & + & - & - & - \\
\hline PKS1C & - & - & - & - & - & + & - & - & - & - & - & - & - & - & - & - & - & - \\
\hline PKG1C & - & - & - & - & - & + & - & - & - & - & - & - & - & - & - & - & - & - \\
\hline PDS105 & - & + & - & - & + & - & - & - & - & - & - & - & - & + & - & - & - & - \\
\hline PGS121 & - & - & + & - & - & + & - & - & - & - & - & - & - & - & - & - & - & - \\
\hline PGS123 & - & - & + & - & - & + & - & - & - & - & - & - & - & - & - & - & - & - \\
\hline PGS124 & - & - & + & - & - & - & - & - & - & - & - & - & - & - & - & - & - & - \\
\hline
\end{tabular}


A comparative study of disc diffusion and microtiter plate methods was done in which the latter method used resazurin dye as an indicator is highly recommended. This is because it produced fast and constant repeat results and reliable. It is important to choose the most appropriate method for screening a high number of samples, especially from the environmental sources. In this study, there was no antimicrobial activity exhibited from hexane extract, therefore the results were excluded. It was also noticed that none of the isolates either tested from direct broth culture or solvent extraction was active against Gram-negative test organisms. This is probably due to Gram-negative bacteria possess an outer lipopolysaccharide membrane, protein, and phospholipids which are attached to thin layers of peptidoglycan that serves as a barrier for antibacterial drugs [41] and makes it difficult to invade the cells. Positive screenings of bioactive compounds produced by actinomycetes isolates against Gram-negative bacteria were reported by [18], [22]. In [22] reported that 20 out of 55 actinomycetes isolated from soil sample of Karanjal region in Sundarbans were produced antibiotic against one or more Gram-negative pathogenic bacteria such as Shigella boydii, Shigella flexneri-AN-31153, Shigella sonnei, Pseudomonas, Shigella dysenterriae type-1, Vibrio cholera0139, Salmonella typhi-Ao-12014, Plesiomonas, Hafnia spp., Vibrio cholera-OGET and Escherichia coli-186LT.

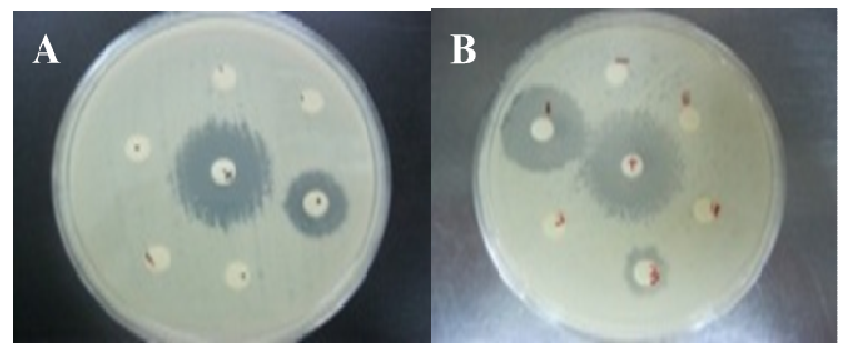

Fig. 4 The (A) macroscopic and (B) microscopic characteristics of Saccharomonospora sp. (PMS2B)

\section{CONCLUSION}

In the current investigation, Malaysian mangrove soil actinomycetes in were successfully isolated and identified in which 3 different genera have been discovered. This study also showed that local isolates have potential to produce good antimicrobial agents. Microdilution plate method is recommended for screening antimicrobial properties from a higher number of samples especially from natural sources. The present results will form the basis for selection of actinomycetes isolates for further investigation in their potential discovery of new natural bioactive compound. Further studies which intended to screen inhibitor of $\beta$-lactamase and to isolate and elucidate its active metabolites from mangrove actinomycetes have been initiated.

\section{ACKNOWLEDGMENT}

The authors thank the Institute of Graduate Studies and Faculty of Applied Sciences, Universiti Teknologi MARA (UiTM) Shah Alam, Selangor for providing funds and facilities for this study.

\section{REFERENCES}

[1] K. Amrita, J. Nitin, and C. S. Devi, "Novel bioactive compounds from mangrove derived actinomycetes," International Research Journal of Pharmacy, vol. 3, pp. 25-29, Sep. 2012.

[2] V. Knight, J. J. Sanglier, D. DiTullio, S. Braccili, P. Bonner, J. Waters, D. Hughes, and L. Zhang, "Diversifying microbial natural products for drug discovery," Applied Microbiology and Biotechnology, vol. 62, pp. 446-458, Oct. 2003.

[3] R. Costanza, R. d'Arge, R. De Groot, S. Farber, M. Grasso, B. Hannon, K. Limburg, S. Naeem, R. V. O'Neill, J. Paruelo, and R. G. Raskin, The Value of the World's Ecosystem Services and Natural Capital (1997), ser. The Globalization and Environment Reader. New Jersey, USA: John Wiley \& Sons, 2016.

[4] B. S. Wang, S. C. Liang, W. Y. Zhang, and Q. J. Zan, "Mangrove flora of the world," Acta Botanica Sinica, vol. 45, pp. 644-653, Jun. 2003.

[5] K. Hong, A. H. Gao, Q. Y. Xie, H. Gao, L. Zhuang, H. P. Lin, H. P. Yu, J. Li, X. S. Yao, M. Goodfellow, and J. S. Ruan, "Actinomycetes for marine drug discovery isolated from mangrove soils and plants in China," Journal of Marine Drugs, vol. 7, pp. 2444, Jan. 2009.

[6] R. C. Patil, A. D. Mule, G. V. Mali, R. R. Tamboli, R. M. Khobragade, S. K. Gaikwad, V. I. Katchi, and D. Patil, "Isolation of marine actinomycetes from the mangrove swamps for biotechnological exploration," Journal of Life Sciences, vol. 5, pp. 1030-1036, 2011.

[7] I. Ara, T. Kudo, A. Matsumoto, Y. Takahashi, and S. Omura, "Nonomuraea bangladeshensis sp. nov. and Nonomuraea coxensis sp. nov.," International Journal of Systematic and Evolutionary Microbiology, vol. 57, pp. 1504-1509, 2007.

[8] I. Ara, A. Matsumoto, M. A. Bakir, T. Kudo, S. Omura, and Y. Takahashi, "Actinomadura maheshkhaliensis sp. nov., a novel actinomycete isolated from mangrove rhizosphere soil of Maheshkhali, Bangladesh," Journal of General Applied Microbiology, vol. 54, pp. 335-342, 2008.

[9] M. Sharma, "Actinomycetes: Sources, identification, and their applications," International Journal of Current Microbiology and Applied Sciences, vol. 3, pp. 801-832, 2014.

[10] M. Goodfellow and S. T. Williams, "Ecology of actinomycetes," Annual Review of Microbiology, vol. 37, pp. 189-216, Oct. 1983.

[11] A. J. McCarthy and S. T. Williams, "Actinomycetes as agents of biodegradation in the environment-A review," Gene, vol. 115, pp. 189-192, Jun. 1992.

[12] J. E. Stach and A. T. Bull, "Estimating and comparing the diversity of marine actinobacteria," Antonie van Leeuwenhoek, vol. 87, pp. 3-9, Jan. 2005.

[13] C. K. Wilkins, "Volatile metabolites from actinomycetes," Chemosphere, vol. 32, pp. 1427-1434, Apr. 1996.

[14] H. Schrempf, "Recognition and degradation of chitin by streptomycetes," Antonie van Leeuwenhoek, vol. 79, pp. 285-289, Sep. 2001.

[15] R. M. Gulve and A. M. Deshmukh, "Antimicrobial activity of the marine actinomycetes," International Multidisciplinary Research Journal, vol. 2, pp. 16-22, Mar. 2012.

[16] H. Bredholt, H. Fjæruik, G. Johnsen, and S. B. Zotchev, "Actinomycetes from sediments in the Trondheim Fjord, Norway: Diversity and biological activity," Marine Drugs, vol. 6, pp. 12-24, Feb. 2008.

[17] R. Solanki, M. Khanna, and R. Lal, "Bioactive compounds from marine actinomycetes," Indian Journal of Microbiology, vol. 48, pp. 410-431, Dec. 2008.

[18] K. S. Kumar, R. Haritha, Y. S. Y. V. J. Mohan, and T. Ramana, "Screening of marine actinobacteria for antimicrobial compounds," Journal of Microbiology, vol. 6, pp. 385-393, Apr. 2011.

[19] L. Zhang, R. An, J. Wang, N. Sun, S. Zhang, J. Hu, and J. Kuai, "Exploring novel bioactive compounds from marine microbes,' Current Opinion in Microbiology, vol. 8, pp. 276-281, Jun. 2005.

[20] A. T. Bull, Microbial Diversity and Biosprospecting. Washington, USA: American Society for Microbiol Press, 2004.

[21] M. Kawato and R. Shinobu, "On Streptomyces herbaricolor sp. Nov., supplement: A simple technique for microscopical observation," Memoirs of the Osaka University of the Liberal Arts and Education. B, Natural science, vol. 8, pp. 114-119, 1960.

[22] M. Arifuzzaman, M. R. Khatun, and H. Rahman, "Isolation and screening of actinomycetes from Sundarbans soil for antibacterial 
activity," African Journal of Biotechnology, vol. 9, pp. 4615-4619, Jul. 2010.

[23] X. L. Cui, P. H. Mao, M. Zeng, W. J. Li, L.P. Zhang, L. H. Xu, and C. L. Jiang, "Streptimonospora salina gen. nov., sp. nov., a new member of the family Nocardiopsaceae," International Journal of Systematic and Evolutionary Microbiology, vol. 51, pp. 357-363, Mar. 2001.

[24] S. D. Sarker, L. Nahar, and Y. Kumarasamy, "Microtitre platebased antibacterial assay incorporating resazurin as an indicator of cell growth, and its application in the in vitro antibacterial screening of phytochemicals," Methods, vol. 42, pp. 321-342, Aug. 2007.

[25] C. Giri, E. Ochieng, L. L. Tieszen, Z. Zhu, A. Singh, T. Loveland, J. Masek, and N. Duke, "Status and distribution of mangrove forests of the world using earth observation satellite data," Global Ecology and Biogeography, vol. 20, pp. 154-159. Jan. 2010.

[26] R. Usha, P. Ananthaselvi, C. K. Venil, and M. Palaniswamy, "Antimicrobial and antiangiogenesis activity of Streptomyces parvulus KUAP106 from mangrove soil," European Journal of Biological Sciences, vol. 2, pp. 77-83, 2010.

[27] J. Xu, Y. Wang, S. J. Xie, J. Xu, J. Xiao, and J. S. Ruan, "Streptomyces xiamenensis sp. nov., isolated from mangrove sediment," International Journal of Systematic and Evolutionary Microbiology, vol. 59, pp. 472-476, Mar. 2009.

[28] K. Sukesh and S. G. P. Vincent, "Purification and characterization of secondary metabolites of marine actinomycetes antagonistic to pseudomonas aeruginosa," International Journal of Pharmacy and Pharmaceutical Science Research, vol. 6, pp. 12-15, 2016.

[29] M. Hayakawa and H. Nonomura, "Humic acid-vitamin agar, a new medium for the selective isolation of soil actinomycetes," Journal of Fermention Technology, vol. 65, pp. 501-509, Dec. 1987.

[30] A. T. Bull and J. E. M. Stach, "Marine actinobacteria: New opportunities for natural product search and discovery," Trends in Microbiology, vol. 15, pp. 491-499, Nov. 2007.

[31] P. R. Jensen, B. S. Moore, and W. Fenical, "The marine actinomycete genus Salinispora: A model organism for secondary metabolite discovery," Natural Product Reports, vol. 32, pp. 738$751,2015$.

[32] P. Shrivastava, R. Kumar, M. S. Yandigeri, N. Malviya, and D. K. Arora, "Isolation and characterization of streptomycetes with plant growth promoting potential from mangrove ecosystem," Polish Journal of Microbiology, vol. 64, pp. 339-349, Jan. 2015.

[33] S. Kaur, H. P. Kaur, and G. Kaur, "Isolation and characterization of antibiotic producing actinomycetes from agriculture soil," World Journal of Pharmacy and Pharmaceutical Sciences, vol. 5, pp. 1109-1117, 2016
[34] C. B. A. de Menezes, R. S. Afonso, W. R. de Souza, M. Parma, I. S. de Melo, T. D. Zucchi, and F. Fantinatti-Garboggini, "Gordonia didemni sp. nov. an actinomycete isolated from the marine ascidium Didemnum sp.," Antonie van Leeuwenhoek, vol. 109, pp. 297-303, Feb. 2016.

[35] H. Wu, Y. Wang, L. Yuan, Y. Mao, W. Wang, L. Zhu, P. Wu, C. Fu, R. Müller, D. T. Weaver, and L. Zhang, "Inactivation of SACE_3446, a TetR family transcriptional regulator, stimulates erythromycin production in Saccharopolyspora erythraea,' Synthetic and Systems Biotechnology, vol. 1, pp. 39-46, Mar. 2016.

[36] S. Yin, Z. Li, X. Wang, H. Wang, X. Jia, G. Ai, Z. Bai, M. Shi, F. Yuan, T. Liu, and W. Wang, "Heterologous expression of oxytetracycline biosynthetic gene cluster in Streptomyces venezuelae WVR2006 to improve production level and to alter fermentation process," Applied Microbiology and Biotechnology, pp. 1-10, 2016.

[37] N. Lomovskaya, L. Fonstein, X. Ruan, D. Stassi, L. Katz, and C. R. Hutchinson, "Gene disruption and replacement in the rapamycin producing Streptomyces hygroscopicus strain ATCC 29253,' Microbiology, vol. 143, pp. 875-883, Mar. 1997.

[38] S. Dharmaraj, "Marine Streptomyces as a novel source of bioactive substances," World Journal Microbiology and Biotechnology, vol. 26, pp. 2123-2139, Dec. 2010

[39] P. R. Jensen, B. S. Moore, and W. Fenical, "The marine actinomycete genus Salinispora: A model organism for secondary metabolite discovery," Natural Product Reports, vol. 32, pp. 738$751,2015$.

[40] S. J. Wu, S. Fotso, F. Li, S. Qin, and H. Laatsch, "Amorphane sesquiterpenes from a marine Streptomyces sp.," Journal of Natural Products, vol. 70, pp. 304-306, Feb. 2007.

[41] M. C. Struelens, The Problem of Resistance, ser. Antibiotic and Chemotherapy: Anti-Infective Agents and Their Use in Therapy. Amsterdam, The Netherlands: Elsevier, 2003.

[42] I. M. Yassin, A. Zabidi, M. S. A. M. Ali, N. M. Tahir, H. A Hassan, H. Z. Abidin, and Z. I. Rizman, "Binary particle swarm optimization structure selection of nonlinear autoregressive moving average with exogenous inputs (NARMAX) model of a flexible robot arm," International Journal on Advanced Science, Engineering and Information Technology, vol. 6, pp. 630-637, Oct. 2016

[43] M. N. M. Nor, R. Jailani, N. M. Tahir, I. M. Yassin, Z. I. Rizman, and R. Hidayat, "EMG signals analysis of BF and RF muscles in autism spectrum disorder (ASD) during walking," International Journal on Advanced Science, Engineering and Information Technology, vol. 6, pp. 793-798, Oct. 2016. 